\title{
(Buscando) Os efeitos sociais da morfologia arquitetônica
}

\author{
(Looking for) The social effects of architectural morphology
}

Vinicius M. Netto ${ }^{[a]}$, Julio Celso Vargas ${ }^{[b],}$ Renato T. de Saboya ${ }^{[c]}$

[a] Doutor em Advanced Architectural Studies, University College London, professor adjunto no Departamento de Urbanismo da Universidade Federal Fluminense (UFF), Niterói, RJ - Brasil, e-mail: v1n1netto@yahoo.co.uk

[b] Doutorando em Sistemas de Transporte pela Universidade Federal do Rio Grande do Sul (UFRGS), professor auxiliar, Departamento de Urbanismo da Universidade Federal do Rio Grande do Sul (UFRGS), Porto Alegre, RS - Brasil, e-mail: jcelso@arqs.com

[c] Doutor em Gestão Territorial pela Universidade Federal de Santa Catarina, professor adjunto no curso de Arquitetura e Urbanismo da Universidade Federal de Santa Catarina (UFSC), Florianópolis, SC - Brasil, e-mail: rtsaboya@gmail.com

\section{Resumo}

Uma das ideias mais centrais e talvez menos esclarecidas em arquitetura e estudos urbanos - sobretudo desde o trabalho seminal de Jacobs até as recentes ênfases da economia urbana - diz respeito ao papel da forma arquitetônica na "vitalidade urbana", um conjunto de qualidades sociais e microeconômicas de nossas cidades. Entretanto, edifícios podem realmente afetar seus entornos urbanos? Teriam morfologias distintas efeitos também distintos sobre o que ocorre nos espaços públicos? Este artigo investiga a forma construída como condição da copresença e a atividade social e econômica no espaço urbano - dinâmicas locais com implicações de ampla escala na cidade. Propõe uma abordagem para identificar os efeitos da forma arquitetônica, de modo a distingui-los dos efeitos de outros aspectos da estrutura urbana como a acessibilidade, e verificar de fato sua existência e, se confirmada, sua extensão. A abordagem é aplicada em um estudo empírico em 24 áreas no Rio de Janeiro. Finalmente, o artigo lança os fundamentos de uma teoria probabilística dos efeitos da arquitetura que visa contribuir para uma resposta mais precisa a uma questão que captura a imaginação espacial: o quanto a arquitetura importa para a vitalidade urbana?

Palavras-chave: Efeitos sociais. Morfologia arquitetônica. Tipologia. Vitalidade urbana.

\section{Abstract}

From Jacobs' seminal insights to recent works in urban economics, one of the most emphasized - and least closely examined - notions in urban studies is the role of architectural and urban form in the "vitality" of our cities, a set of social and microeconomic qualities. However, can buildings really affect their urban surroundings? 
Would distinct architectural morphologies have distinct effects over local socioeconomic processes? This paper looks into built forms as a condition for co-presence and social activity in urban space. It advances an approach able to identify precisely the existence and extension of effects of architectural morphology on local socioeconomic processes, with potential large-scale effects, in a way to disentangle them from the effects of urban structures such as the street network. We apply the approach in an empirical study in twenty-four areas in Rio de Janeiro. Finally, the paper establishes the grounds for a probabilistic theory of the social effects of architecture, an approach proposed to help answering more precisely a question that puzzles the spatial imagination: how does architecture matter to urban vitality?

Keywords: Social effects. Architectural morphology. Typology. Urban vitality.

\section{Introdução}

[...] há dois tipos de densidade [...] A "densidade crua" é encontrada em áreas repletas de edifícios mais e mais altos que, sozinhos, não geram inovação ou desenvolvimento econômico. Diferentemente, a "densidade Jacobs" estimula a interação ao nível da rua e amplia o potencial de contato informal entre pessoas em espaços públicos a qualquer momento. Ela torna encontros e a construção de redes [sociais] mais prováveis (FLORIDA, 2012).

Uma das ideias mais centrais e talvez menos esclarecidas em arquitetura e nos estudos urbanos diz respeito ao papel da forma arquitetônica e urbana na "vitalidade" de nossas cidades. A vitalidade dos espaços urbanos é um fenômeno que vem sendo abordado com ênfase sobretudo desde o trabalho seminal de Jane Jacobs (2000). Muitos autores se dedicaram a refletir sobre quais aspectos das edificações e dos espaços públicos teriam a capacidade de estimular vitalidade, entendida como um conjunto de condições encontradas em espaços em que há intensa presença de pessoas nas ruas, grupos em interação e trocas microeconômicas. 0 papel das densidades e da forma urbana retorna agora à atenção, sobretudo associado ao tema da interatividade e inovação, enfatizado recentemente na economia urbana - de modo contraditório - por Glaeser (2010), Gordon e Ikeda (2011) e Florida (2012) ${ }^{1}$.

Entretanto, teria a forma da edificação algum papel na vitalidade? $\mathrm{Ou}$, mais especificamente, teriam morfologias arquitetônicas distintas efeitos também distintos sobre o que ocorre nos espaços públicos? Se há tal influência, qual sua extensão? 0 quanto a arquitetura impacta seus entornos urbanos?

0 presente trabalho desenvolve uma abordagem para identificar os efeitos da forma arquitetônica sobre processos socioeconômicos locais com implicações de ampla escala - de modo a distingui-los dos efeitos de outros aspectos da estrutura urbana como o sistema viário, e verificar de fato sua existência e extensão.

Entender os impactos de diferentes morfologias arquitetônicas sobre a vitalidade de entornos urbanos significa entender as implicações entre essa morfologia e dinâmicas mais amplas. Esse problema está no cerne de uma definição mais precisa e consistente do termo "sustentabilidade urbana". Essa preocupação ganha maior sentido no contexto brasileiro, uma vez que podemos observar em nossas cidades a reprodução de tipos de arquitetura e padrões de urbanização fixados por modelos espaciais e preceitos de produção imobiliária a partir de critérios usualmente limitados à otimização dos processos construtivos e sua rentabilidade.

Há, entretanto, desconhecimento da real extensão das possíveis influências da tipologia e configurações urbanas sobre as condições da apropriação social do espaço. Gravemente, temos observado ainda uma dissolução do tecido urbano em cidades brasileiras - uma substituição progressiva de tipos de edifícios tradicionais por um tipo predominante no mercado de produção, de ligações mais frágeis

\footnotetext{
${ }^{1}$ Embora todos esses autores concordem sobre a importância da densidade, Glaeser afirma que a verticalização é fator-chave de cidades interativas e criativas. Em contraponto, estudos empíricos de Gordon e Ikeda, apoiados por Florida, apontam como determinante o papel das densidades horizontais a que chamam "jacobianas".
}

urbe. Revista Brasileira de Gestão Urbana (Brazilian Journal of Urban Management), v. 4, n. 2, p. 261-282, jul./dez. 2012 
com o espaço público. Essa crescente rarefação urbana, suspeita-se, seria acompanhada de aumento das distâncias intraurbanas, diluição do movimento de pedestres e da vida microeconômica local, problemas de segurança pública e novas formas de segregação socioespacial.

Buscamos examinar se a dissolução do tecido urbano implicaria em uma dissolução da apropriação do espaço público - e retornar a uma questão que tem capturado a imaginação arquitetônica e urbana: o quanto a arquitetura importa para a vitalidade urbana?

\section{Vitalidade urbana como efeito da morfologia arquitetônica}

A possibilidade de a arquitetura ter efeitos refere-se aos impactos da edificação para além do estético e perceptivo - sobre as ações que ocorrem fora do seu perímetro, mas atreladas a ela, tais como o movimento e acesso a atividades, a intensidade variada de apropriação do espaço público e a densidade de encontros no âmbito da rua. Esses fenômenos são ancorados na interface espaço aberto-construído, entre a pele do edifício e a rua. São componentes elementares na relação espaço urbano-vida social, no status do espaço como condição para a produção dos fatores basilares da vida social. Ao envolver encontros no espaço público e a possibilidade de acesso ao espaço construído, essa relação envolve também potencial de comunicação e a constituição de trocas sociais, políticas e microeconômicas que se manifestam localmente.

As relações entre ação, espaço público aberto, espaço interno da edificação e as atividades que esta abriga consistem na verdade na ponta visível de uma rede de alta complexidade, conectada a uma infinidade de atores cujas ações são realizadas em outros lugares e tempos - uma rede de ações e circulação de informação e artefatos que se completa no momento da interação e troca final no interior da arquitetura e na sua relação aos canais do espaço público. A escala do edifício e suas relações imediatas em complexos urbanos colocam-se como uma das forças estruturantes da cidade, sobre as quais as relações macroscópicas tornam-se reconhecíveis e nas quais as dinâmicas cotidianas reproduzem processos sociais e microeconômicos geograficamente mais amplos.

A atenção a essa escala da constituição das estruturas urbanas e seus impactos não é exatamente nova. Jacobs (2000) já atentava para a importância dos elementos de "constituição", os componentes da forma arquitetônica diretamente ligados à rua, como aberturas e fachadas. Gehl (2011) defende a conexão visual e física entre edificação e espaço público através de espaços de transição. Aborda também a posição da edificação no lote, diferenciando edificações afastadas das ruas daquelas diretamente conectadas a elas. No Brasil, a atenção a essa problemática tem aparecido sob forma de observações empíricas como a de Santos e Vogel (1985) sobre a relação entre ocasiões de contato face a face, o uso de grades e a distância entre casa e rua. Holanda (2002) aponta a relação entre número de portas voltadas para o espaço público e a relação fachada-rua necessária na animação do espaço público. Vargas (2003) trata da forma do quarteirão e ruas de alta centralidade como fatores de vitalidade; e o papel do tipo e seus efeitos sociais sobre o entorno são conceituados por Netto (2006). Entretanto, essas leituras do papel da forma arquitetônica-urbana não formulam o problema em um enunciado teórico sistemático e demonstrável empiricamente ${ }^{2}$. É o que buscamos fazer neste trabalho: desenvolver um caminho teórico e metodológico para verificar se existem e, em caso positivo, qual a extensão dos efeitos da morfologia edificada sobre o que ocorre em seus entornos.

Uma nota sobre a definição de "efeitos" e "vitalidade urbana", o recorte social e espacial e a metodologia aqui adotados. A possibilidade e natureza dos efeitos sociais da arquitetura são temas mais intuídos que problematizados explicitamente. São de longe menos tematizados que os aspectos estéticos. Sua captura é difícil: terminam rejeitados em interpretações pejorativas como sendo

\footnotetext{
${ }^{2}$ A ideia de que a arquitetura tenha impactos sociais, apesar de vista em certos autores menos ou mais sistematicamente, não é um pressuposto no campo: a ênfase na prática e no ensino segue nos aspectos da funcionalidade interna e estética externa. De fato, não temos verificação empírica dessa relação e sua extensão, com exceção ao nível das densidades de trabalhos como de Gordon e Ikeda (2011).
} 
"subjetivos" (e, portanto, supostamente descartáveis quando conveniente) quando na verdade se referem a fatores que envolvem as pessoas em suas interações mediadas pelo espaço e não apenas suas percepções. Por envolver o que ocorre fora de nossas mentes, podemos, contudo, reconhecer seus traços, evidenciar sua existência. É o que desejamos fazer neste trabalho. Mas precisamos capturar esses traços do modo mais direto possível - e mostrar objetivamente sua importância. Usaremos um caminho fortemente empírico e estatístico para tentar reconhecer os efeitos da arquitetura, na forma de possíveis regularidades das coincidências entre fatores espaciais e sociais presentes em áreas urbanas e diferentes cidades e contextos.

Aqui reside um primeiro mal-entendido frequente no campo dos estudos arquitetônicos e urbanos: a visão da análise "quantitativa" de fenômenos como uma redução do simbólico e experiencial, o descarte de tudo o que não é visível e mensurável como inexistente ou irrelevante. Essa visão parece sugerir que tal forma de análise seria "menos humana" que, digamos, os métodos interpretativos ou "qualitativos." Na verdade, a análise estatística é tão humana quanto uma interpretação subjetiva. Nem mais, nem menos. Mas ela tem especificidades: é útil para lidarmos com duas coisas com as quais temos natural dificuldade usando palavras. A linguagem discursiva é poderosa para definir significados conotativos e denotativos, mas seu léxico é surpreendentemente pequeno e impreciso para lidar com o problema das intensidades (palavras como "muito", "pouco", etc. são bastante vagas). A natureza sequencial da fala e escrita ainda nos coloca dificuldades para capturar cognitivamente as teias de relações em fenômenos complexos como cidades, onde aspectos e eventos influenciam outros em várias direções, de modo sincrônico (ocorrem ao mesmo tempo), processual (transcorrem no tempo) e em lugares distintos. Essas são tramas impossíveis de serem descritas discursivamente. Precisamos do complemento de outras linguagens para incorporar completamente o problema das intensidades e das relações - sob pena de não entendermos a riqueza e a extensão das relações entre espaço e prática social.

Buscaremos estudar a vitalidade urbana em um recorte específico. Esse recorte não incluirá nesse momento as formas de sociabilidade em si, mas aspectos sociais anteriores a elas, que as subjazem: a presença dos corpos no espaço urbano.
Reconhecemos que a riqueza das particularidades simbólicas, seus aspectos interpretativos, as formas de relacionamento e afetos serão dimensões da vitalidade. Essas dimensões estão, entretanto, além do foco jacobiano do presente trabalho, ligado sobretudo ao problema das intensidades da copresença no espaço urbano como condição para produção das interações sociais e microeconômicas - dinâmicas que só podem emergir quando há intensidades mínimas de presença humana e que têm a diversidade como consequência. Queremos destacar que a dimensão das intensidades de fenômenos como a copresença é certamente tão relevante quanto a dimensão hermenêutica das trocas sociais e suas motivações. A primeira é condição para a vida social emergir plenamente, em sua diversidade.

É curioso notar como tradições de pesquisa são assentadas em uma dicotomia epistemológica o "qualitativo" e o "quantitativo" - que implica em trazer descontinuidades a coisas que são, na verdade, profundamente ligadas. Tal dualismo se relaciona a uma limitação em reconhecer a posição da teoria frente ao mundo: intensidades são parte dos fenômenos à volta e operam em conjunção com suas diferenças, incluindo aquelas de natureza simbólica. Esse dualismo artificial evidencia uma dificuldade da epistemologia (o modo como entendemos as coisas) mais do que descontinuidades ontológicas (na natureza das coisas em si). Essa é uma dicotomia a ser superada. Precisamos reconhecer essas diferenças como dualidades e não como dualismos. A dimensão das intensidades das presenças e interações e a dimensão dos conteúdos simbólicos da interação e valores subjetivos são complementares e igualmente importantes para a vitalidade urbana. Aqui, trataremos do aspecto presencial, que subjaz processos intersubjetivos e comunicativos.

Diferenças espaciais e sociais entre áreas em uma cidade são parte fundamental deste estudo, dado que desejamos detectar efeitos arquitetônicos que possam estar presentes e ativos mesmo em diferentes contextos. Entendemos que diferentes formas de sociabilidade ocorram e possam intensificar ou reduzir a copresença no espaço público. Certamente, diferenças de valores, cultura e classe podem afetar hábitos de uso do espaço público. Mas como Jacobs, entendemos que a copresença e a interação social e microeconômica são fatores que atravessam diferentes campos sociais e emergem em diferentes 
contextos. São efeitos que se referem a relações entre arquitetura, corpo e dinâmicas sociais profundas, constitutivos de diferenças sociais e desdobramentos psicossociais. Nosso objetivo é verificar se o efeito da arquitetura sobre a copresença pode ser reconhecido mesmo com todas essas diferenças em jogo. Por outro lado, os impactos dessas diferenças sobre o presencial podem e devem ser tema de outros trabalhos.

Agora uma nota sobre o recorte espacial. Reconhecemos que a vitalidade urbana inclui formas de interação e proximidade entre atores e geração de socialidades que certamente podem se manifestar mesmo em espaços de diferentes formas e tipologias, como os subúrbios e os espaços rurais. Focaremos, entretanto, áreas urbanas com a presença (não exclusiva) de tipologias arquitetônicas multifamiliares, analisadas em diferentes níveis de densidade - de modo a evitarmos morfologias e tipologias radicalmente diferentes.

\section{Identificando diferenças na morfologia arquitetônica}

Investigamos os impactos da morfologia arquitetônica por meio do reconhecimento de diferenças ao mesmo tempo profundas e evidentes no tecido urbano, como em áreas na cidade do Rio de janeiro (Centro, Botafogo e Barra da Tijuca) (Figura 1).

Tecidos urbanos apresentam diferentes graus de continuidade e descontinuidade, proximidades e afastamentos entre edificações, implicando diferentes relações entre espaços construídos e o espaço livre público. 0 elemento essencial nesse tecido é o próprio edifício e suas relações. A imensa variedade da forma edificada encontra, entretanto, reduções usuais na literatura e no planejamento urbano, como a dos tipos arquitetônicos, entre eles: (a) o edifício cujos limites coincidem com as divisas do lote urbano, especialmente na parte lateral, (chamado aqui "contínuo"); (b) o edifício livre no lote, caracterizados por afastamentos laterais, explorado sobretudo a partir do modernismo ("isolado"); e (c) um terceiro tipo, composto por uma justaposição dos dois anteriores apresentando um volume basal horizontalizado colado nas divisas e um volume superior isento de contato lateral ("híbrido"). Esses três tipos de formas arquitetônicas, definidos pela posição no lote, o grau de continuidade de suas


Figura 1 - Diferenças morfológicas teriam impactos sobre a apropriação social do espaço?

Fonte: GO0GLE STREET VIEW, 2011; GOOGLE EARTH, 2011.

fachadas e suas relações de permeabilidade com o espaço público, representam uma grande parte das formas produzidas em nossas cidades, contempladas e mesmo prescritas pelos planos diretores municipais.

Agora tentemos relacionar essa diferenciação inicial entre edifícios a fenômenos sociais reconhecíveis em seus entornos. Nossa hipótese é que, mantidas relativamente constantes propriedades como acessibilidade e densidade, o tipo contínuo (a) ampararia mais adequadamente a vida social e microeconômica na escala local ao relacionar-se mais diretamente aos espaços públicos e permitir uma relação intensa entre atividades e pedestres, por meio das fachadas contíguas (Figura 2).

Por outro lado, o tipo isolado (b) teria efeitos opostos ao do tipo (a), como função do quão amplos são seus afastamentos em relação à rua e aos edifícios laterais. As características de (b) ainda implicariam em aumento de distâncias entre edificações, trariam dificuldades à implantação de atividade comercial 


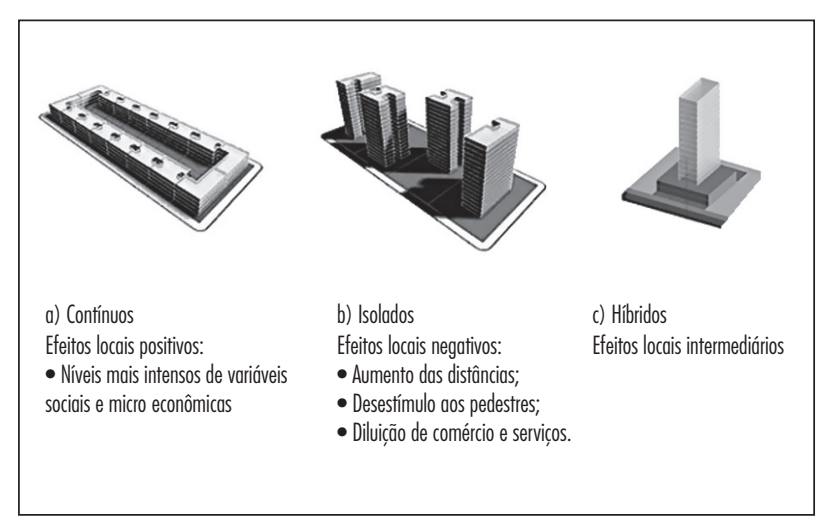

Figura 2 - A hipótese dos efeitos sociais da arquitetura Fonte: Dados da pesquisa.

a e à passagem entre o interior das edificações e os espaços públicos, e afetariam a apropriação do espaço público pelos pedestres, com efeitos potenciais de larga escala quanto ao desempenho urbano, tais como o aumento da dependência veicular. Assim, quanto mais dominante for (b) em uma área urbana, mais rarefeita seria a presença de pedestres e a atividade microeconômica. Entre esses dois conjuntos de efeitos opostos, um tipo (c) híbrido teria efeitos intermediários, podendo ser pouco positivos ou negativos a depender do modo como a base é tratada na sua relação com o espaço público.

Aspectos arquitetônicos, como o grau de porosidade das fachadas (densidade de aberturas), fechamento do lote, densidade construída etc. se colocariam como itens que intensificariam ou não as tensões entre formas construídas, e entre estas e o corpo, potencialmente relevantes para a copresença nas ruas e a atividade social e econômica urbana.

Buscaremos evidências da existência dessas tensões em um estudo empírico, no qual confrontaremos estatisticamente as distribuições de diferentes arranjos dessas características espaciais e a presença da atividade social nesses espaços. A teia de relações entre os principais aspectos espaciais e sociais - a teia que constitui nossas hipóteses - pode ser vista na Figura 3.

\section{Caminhos para encontrar os efeitos sociais da arquitetura}

Entretanto, se nosso objetivo é identificar os impactos sociais de um componente urbano par-

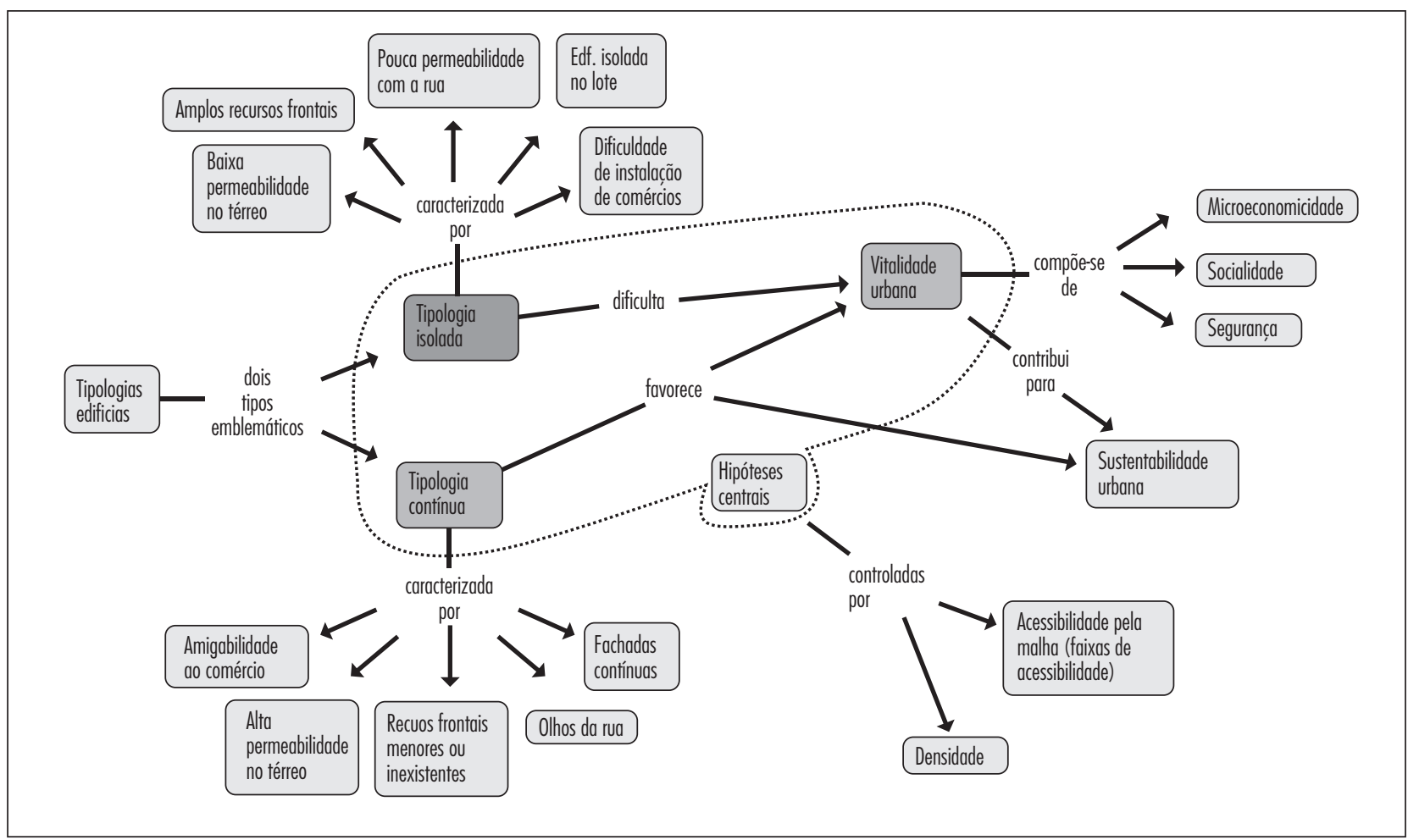

Figura 3 - Esquema ilustrativo do problema de pesquisa e suas hipóteses Fonte: Dados da pesquisa. 
ticular - a morfologia arquitetônica - precisamos de uma forma de isolar seus efeitos dos de outros componentes do sistema urbano. Entre esses outros componentes, aquele considerado isoladamente como o mais influente por grande parte da literatura urbana é a relação entre posições no espaço urbano, a acessibilidade ${ }^{3}$. Outros aspectos que tendem a influenciar o potencial de uso dos espaços públicos são as densidades populacional e arquitetônica. Em condições de neutralidade em outros componentes, ambientes urbanos mais densos tendem a ter movimento pedestre mais intenso, na medida em que envolvem mais atividades para a mesma quantidade de espaços públicos e mais pessoas em potencial.

Precisamos definir um método para isolar a influência desses fatores da configuração arquitetônica daqueles da estrutura urbana sobre a vitalidade dos espaços públicos, representada por (i) intensidade de movimento de pedestres, (ii) presença de grupos e indivíduos em uso estático da rua, e (iii) presença de atividades comerciais e de serviços, como indicadores de trocas microeconômicas. Entre possibilidades metodológicas, optamos por uma forma bastante simples. Propomos a seguinte ideia: pesquisar áreas urbanas de níveis similares de acessibilidade. Confrontaremos as variações na morfologia arquitetônica com as variações nos aspectos da vitalidade urbana nessas áreas. Essa ideia é amparada ainda numa observação. Há uma relação linear entre acessibilidade e movimento amplamente encontrada empiricamente ${ }^{4}$ - quando a acessibilidade proporcionada pela malha viária aumenta, fatores-chave da vitalidade (como o movimento pedestre) tendem a aumentar. Mas não tão simplesmente. Ruas (pontos no gráfico) de mesmo nível de acessibilidade podem ter substancial diferença de fatores de vitalidade. Essa relação não pode ser explicada, portanto, apenas pela acessibilidade (Figura 4).

Podemos ver que há variações nessa relação: o aumento gradual da acessibilidade não é perfeitamente replicado em um aumento do movimento pedestre - duas ruas de mesma acessibilidade apresentam com frequência volumes pedestres distintos. E nem poderia ser o caso de uma equivalência perfeita: cidades têm inúmeros fatores intervindo no movimento pedestre, incluindo fatores



Figura 4 - Relação acessibilidade-vitalidade

Fonte: Dados da pesquisa.

imprevisíveis como as decisões de cada pedestre. Na verdade, considerando tantos outros vetores urbanos, é surpreendente que haja uma relação consistente entre acessibilidade e movimento pedestre, como a encontrada empiricamente.

Assim, nem toda variação no movimento é explicada pela acessibilidade proporcionada pela malha. Podemos ver isso claramente ao selecionarmos uma faixa bastante estreita de variação de acessibilidade, e ver que ela corresponde a uma faixa nem tão estreita de intensidades de movimento (veja a Figura 2 novamente). Essas variações no movimento não são explicadas pela acessibilidade. Mesmo as distribuições das atividades na cidade se mostram com variações similares.

Aqui está o ponto central do problema que queremos capturar. Propomos que exatamente essas diferenças "mais que proporcionais" entre acessibilidade e movimento pedestre são o lugar ativo da arquitetura e das diferenças na morfologia arquitetônica. Nessas diferenças estariam "os efeitos da arquitetura".

Vejamos como verificar tal hipótese. Nosso método indica que, se analisarmos um conjunto de ruas em uma cidade dentro de uma mesma faixa de acessibilidade, as diferenças de movimento pedestre encontradas nessas ruas estariam aproximadamente livres dos efeitos da acessibilidade. A percepção desses efeitos estaria limitada, obviamente, pela eficácia do método empregado para avaliar a acessibilidade,

3 Cf. WEBER, 1909; HANSEN, 1959; HILLIER; HANSON, 1984; HILLIER; PENN; HANSON, 1993.

4 Veja HILLIER; PENN; HANSON, 1993; HILLIER, 1996; PENN et al. 1998. 
assim como pela consideração das diferentes escalas de acessibilidade ativas simultaneamente em um mesmo lugar. Assim, ao minimizarmos os efeitos da configuração do sistema viário nas áreas estudadas, poderemos comparar as variações nos aspectos sociais e econômicos locais com as variações nas características arquitetônicas, e examinar se existem correlações significativas entre elas. A consideração das densidades pode fazer uso da mesma lógica.

\section{Descrevendo e controlando a acessibilidade}

Apesar de a lógica desse método ser simples, ela implica em outras questões metodológicas. Controlar a influência da acessibilidade sobre a vitalidade urbana é uma tarefa difícil, uma vez que ela é penetrante, combinando-se potencialmente com os efeitos de outros padrões urbanos e imersa em contingências. Medidas de acessibilidade topológica parecem ferramentas adequadas para esse propósito, por terem sido bem-sucedidas em prover descrições detalhadas de diferenciação espacial em cidades em uma variedade de contextos e culturas urbanas.

Entretanto, a descrição da acessibilidade envolve ainda outras questões: (i) a medida a ser utilizada para representar a acessibilidade proporcionada pela malha (como as medidas de integração ou escolha); (ii) o entendimento de distância como caminhos mínimos (métrica, geométrica ou topológica); (iii) o raio de acessibilidade a ser considerado (dos raios mais globais da cidade aos mais locais); e (iv) a unidade espacial usada para representar as ruas e espaços públicos (linhas axiais ou segmentos). Selecionamos neste estudo o conjunto composto pela combinação Integração + Distância Topológica + Raio Global (RR) ${ }^{5}$ + Linhas Axiais representando trechos retilíneos de ruas, e segmentos ${ }^{6}$. Para acompanhar o papel de outras escalas de acessibilidade e correlacioná-las com os aspectos socioeconômicos, faremos uso de um monitoramento estatístico

Uma última questão sobre acessibilidade: falamos de olhar para a variação arquitetônica nas ruas de uma mesma faixa de acessibilidade como um modo de identificarmos os possíveis efeitos dela sobre os fenômenos socioeconômicos que ocorrem nessas ruas. Mas será que o nível de acessibilidade em si não influenciaria esses fenômenos? Ruas de alta acessibilidade poderiam ter naturalmente mais pedestres que ruas de baixa acessibilidade, independentes da morfologia arquitetônica, quem sabe interferindo assim na possível influência da arquitetura? Pode haver limiares de acessibilidade a partir dos quais a arquitetura pode estimular a vitalidade, ou não. Para verificarmos essas possíveis interferências, analisaremos áreas e ruas em três faixas distintas de acessibilidade (baixa, média e alta) e, seguindo o mesmo raciocínio, em três faixas de densidade. Devemos buscar áreas que atendam às combinações de acessibilidade e densidade, de modo a termos áreas de características distintas e garantir a representatividade dessas diferenças face ao conjunto morfologicamente diverso da cidade em estudo (Figura 5).

Não há condição - ou necessidade - de estudar todas as áreas de uma cidade. Mas as áreas que atendam essas combinações devem ser selecionadas de forma aleatória e não arbitrariamente, para reduzir riscos de indução das conclusões. Cada uma das combinações, entretanto, deve conter um número

\begin{tabular}{|c|c|c|c|c|c|c|c|}
\hline $\begin{array}{c}\text { Acessibilidade } \\
\text { BAIXA }\end{array}$ & $\begin{array}{l}\text { Densidade BAIXA } \\
\text { Densidade MÉDIA } \\
\text { Densidade ALTA }\end{array}$ & $\begin{array}{l}1 \\
2 \\
3\end{array}$ & $\begin{array}{c}\text { Acessibilidade } \\
\text { MÉDIA }\end{array}$ & $\begin{array}{l}\text { Densidade BAIXA } \\
\text { Densidade MÉDIA } \\
\text { Densidade ALTA }\end{array}$ & $\begin{array}{l}4 \\
5 \\
6\end{array}$ & $\begin{array}{c}\text { Acessibilidade } \\
\text { ALTA }\end{array}$ & $\begin{array}{l}\text { Densidade BAIXA } \\
\text { Densidade MÉDIA } \\
\text { Densidade ALTA }\end{array}$ \\
\hline
\end{tabular}

Figura 5 - Combinações dos níveis de acessibilidade e densidade como critérios de seleção de áreas a serem analisadas em estudos empíricos Fonte: Dados da pesquisa.

\footnotetext{
5 Raio Global é a profundidade média da linha axial mais integrada do sistema urbano e é utilizado para minimizar o efeito de borda (HILLIER, 1996).

6 Para detalhes sobre as razões desta seleção de medida, propriedade e entidade. Cf. NETTO et al. 2012.
} 
de ruas grande o bastante para permitir: (i) uma análise estatisticamente significante; (ii) certa concentração dos trechos de ruas a serem analisados, para facilitar o levantamento; e (iii) boa presença dos tipos arquitetônicos de interesse para o estudo.

\section{O Rio de Janeiro como estudo de caso}

Aplicamos esta abordagem em um estudo empírico de larga escala buscando identificar os efeitos sociais da forma arquitetônica na cidade do Rio de Janeiro. Analisamos a acessibilidade do Rio em 20 faixas, da menor a maior, das quais selecionamos as faixas 7 (baixa), 11 (média) e 17 (alta acessibilidade) ${ }^{7}$. A Figura 6 mostra a distribuição dessas faixas no tecido do Rio. A Figura 7 mostra a distribuição das ruas de acordo com seus níveis de acessibilidade.

Acompanhamos ainda a densidade nessas áreas, distinguindo três grandes faixas (baixa, média e alta). A Figura 8 mostra a distribuição das densidades nos setores censitários que contém as ruas das três faixas de acessibilidade selecionadas.

Esse recorte permite examinar o quanto a acessibilidade geral de uma área pode interferir no potencial da forma arquitetônica no estímulo da vitalidade urbana. No caso do Rio de Janeiro, em função do seu porte, fizemos ainda uma última setorização em três zonas (centro e zona norte, zona sul e zona oeste).

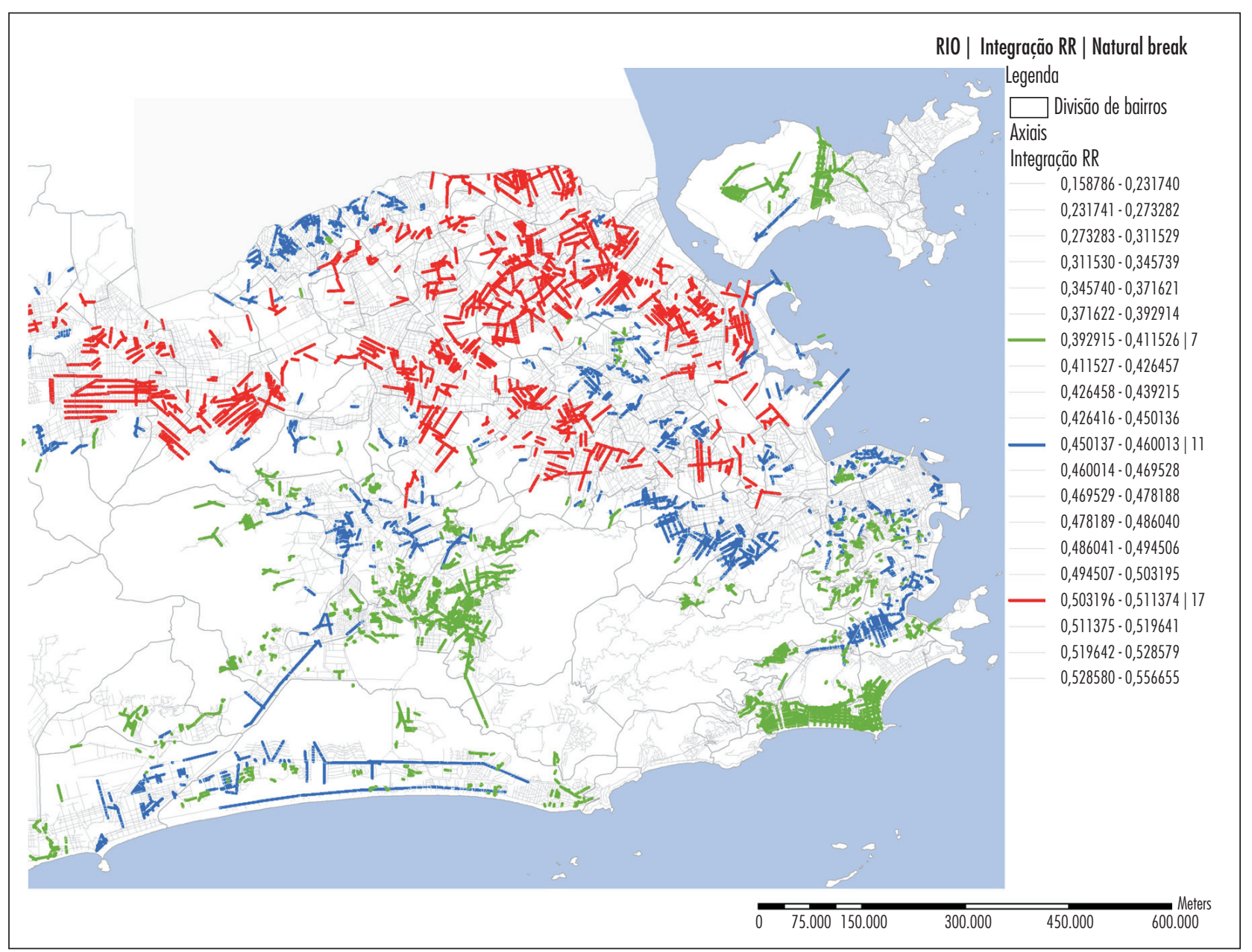

Figura 6 - Os segmentos de ruas nas faixas de acessibilidade alta, média e baixa no Rio de Janeiro Fonte: NETTO et al., 2012.

\footnotetext{
7 Usamos a medida de acessibilidade "integração" adotando o raio equivalente à profundidade do sistema de ruas (linhas axiais) a partir da linha axial mais acessível ou integrada (RR).
} 


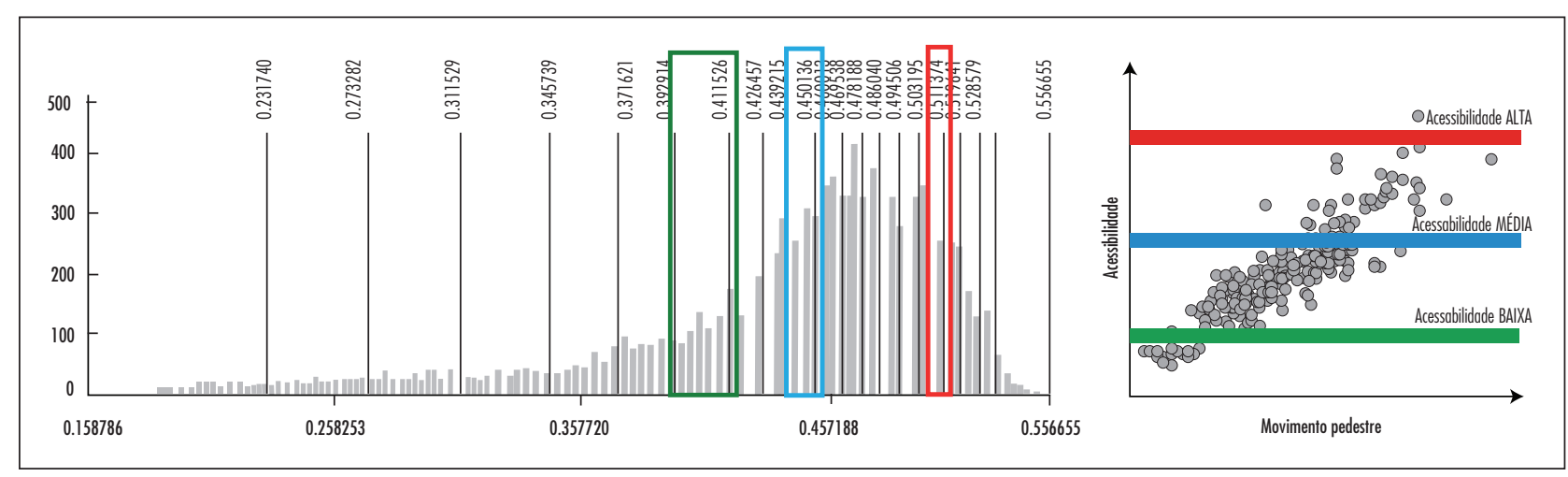

Figura 7 - Histograma do número e distribuição das ruas de acordo com seus valores de integração $0^{8}$ Fonte: NETTO et al., 2012.

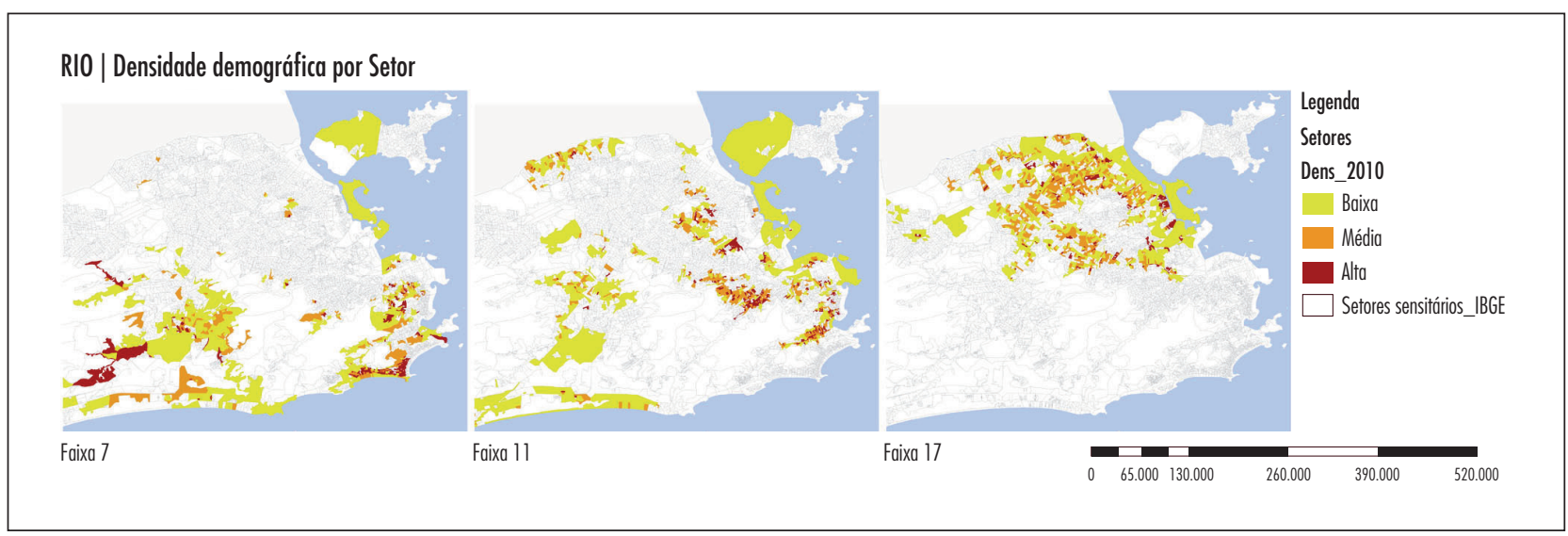

Figura 8 - Distribuição das densidades populacionais (alta, média e baixa) nos setores censitários que contém os segmentos de rua das três faixas de acessibilidade selecionadas

Fonte: NETTO et al., 2012.

Devemos definir quantos segmentos de rua analisar. Esse número depende do número de segmentos nas áreas selecionadas aleatoriamente, de modo a chegarmos a uma amostra representativa e possível de ser levantada. A análise estatística é o meio para essa definição. No caso do Rio de Janeiro, em cada combinação de acessibilidade e densidade, e em cada zona, deveríamos ter 12 segmentos de rua (trechos entre as esquinas do quarteirão) - ou seja, 36 segmentos para cada combinação. Talvez nem todas as combinações possam ser plenamente atendidas: áreas de alta acessibilidade com baixa densidade, por exemplo, tendem a não ocorrer (a economia urbana nos explica que áreas de alta acessibilidade tendem a ser mais procuradas para localização de atividades e produção arquitetônica). Contudo, esse não é o caso do Rio de Janeiro: áreas de alta acessibilidade frequentemente não possuem alta densidade, o que limita a amostragem (compare as Figuras 6 e 8). Encontramos apenas nove segmentos com alta densidade e alta acessibilidade dentro das áreas selecionadas nas faixas. Esse é um sinal de uma interessante "divergência" entre

\footnotetext{
8 Vinte categorias foram geradas baseadas em "natural breaks" (veja NETTO et al., 2012). o Rio de Janeiro tem uma longa "cauda" de ruas segregadas, o que nos levou a escolher a faixa 7 como nível de baixa acessibilidade. À direita, conjuntos de ruas que constituem as faixas de alta (vermelha), média (azul) e baixa (verde) acessibilidades.
} 
padrões urbanos que tenderiam de outro modo a ter níveis similares. Entendemos que a razão para tal divergência seja a rápida expansão urbana, que impacta a hierarquia de acessibilidade sem o acompanhamento imediato da densificação, visível especialmente em áreas na zona norte do Rio de Janeiro.
É importante analisar áreas diferentes entre si para verificarmos se tais diferenças são ativas e o quão basilar é o papel da morfologia arquitetônica para a intensidade da copresença e atividade que emergem nesses espaços (Figuras 9 a 11 - traços roxos nas linhas laranjas são locais de observação pedestre). As áreas resultantes têm o seguinte arranjo (Figura 12).



Figura 9 - Exemplo de área sorteada: Freguesia, bairro residencial de classe média, baixa acessibilidade Fonte: Dados da pesquisa.

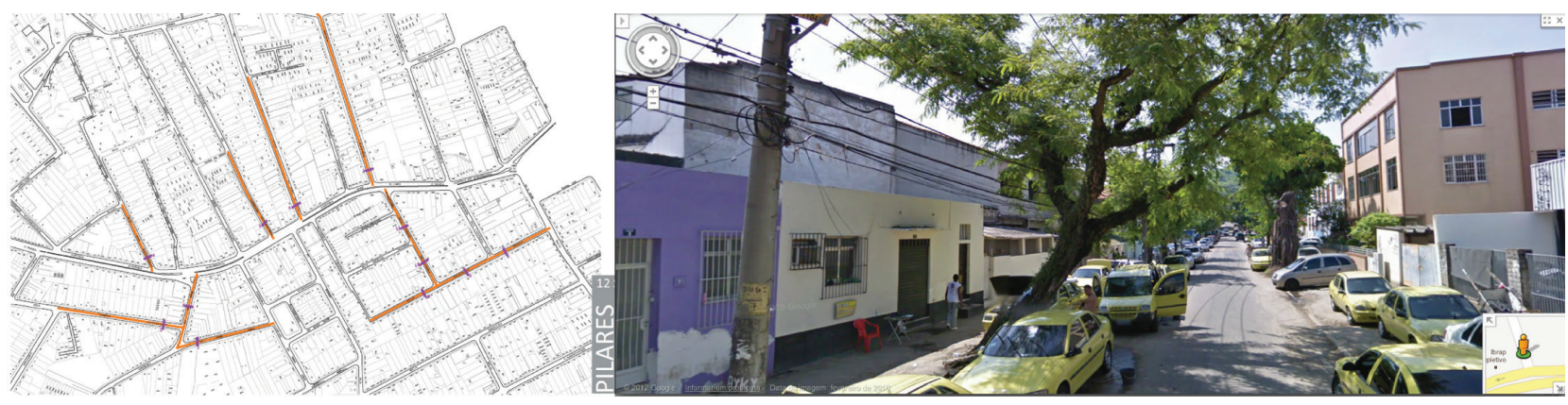

Figura 10 - Pilares, área de classe média-baixa e alta acessibilidade na zona norte do Rio de Janeiro Fonte: Dados da pesquisa.

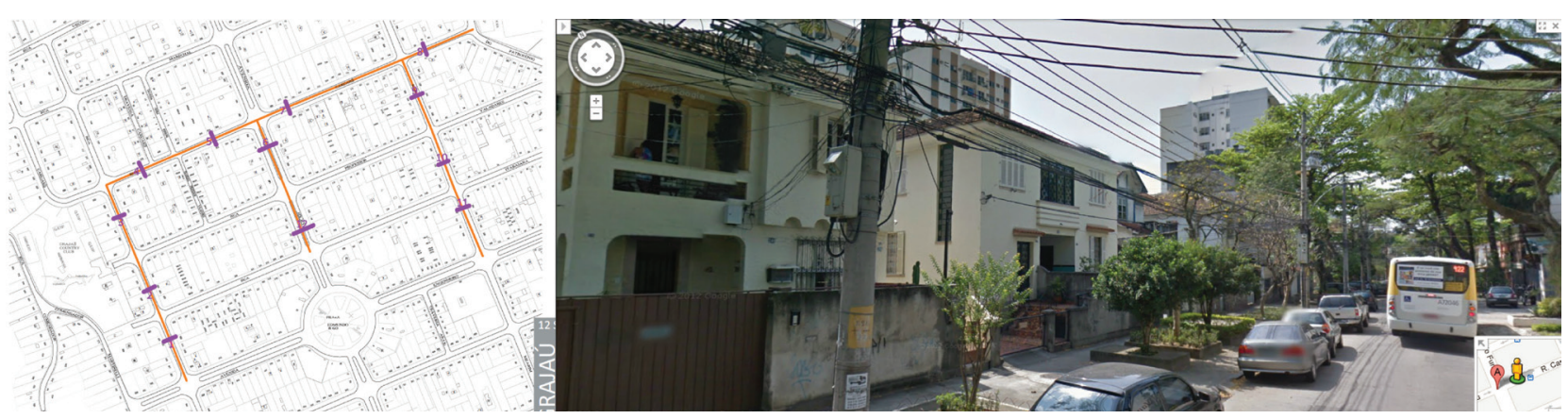

Figura 11 - Grajaú, área de acessibilidade e densidade médias na zona norte Fonte: Dados da pesquisa. 
As 24 áreas selecionadas aleatoriamente no Rio de Janeiro incluem 250 segmentos e cerca de 3.800 edifícios. Observamos pedestres nesses segmentos em seis horários durante um dia de semana. Um mapa final mostra a localização de tais áreas (Figura 13).

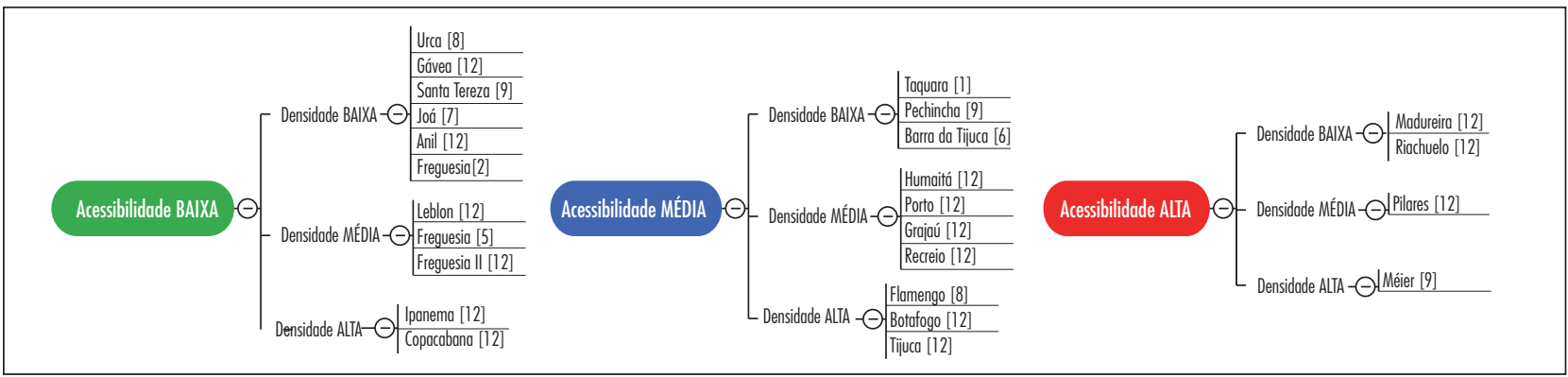

Figura 12 - Seleção de áreas no Rio de Janeiro9

Fonte: Dados da pesquisa.

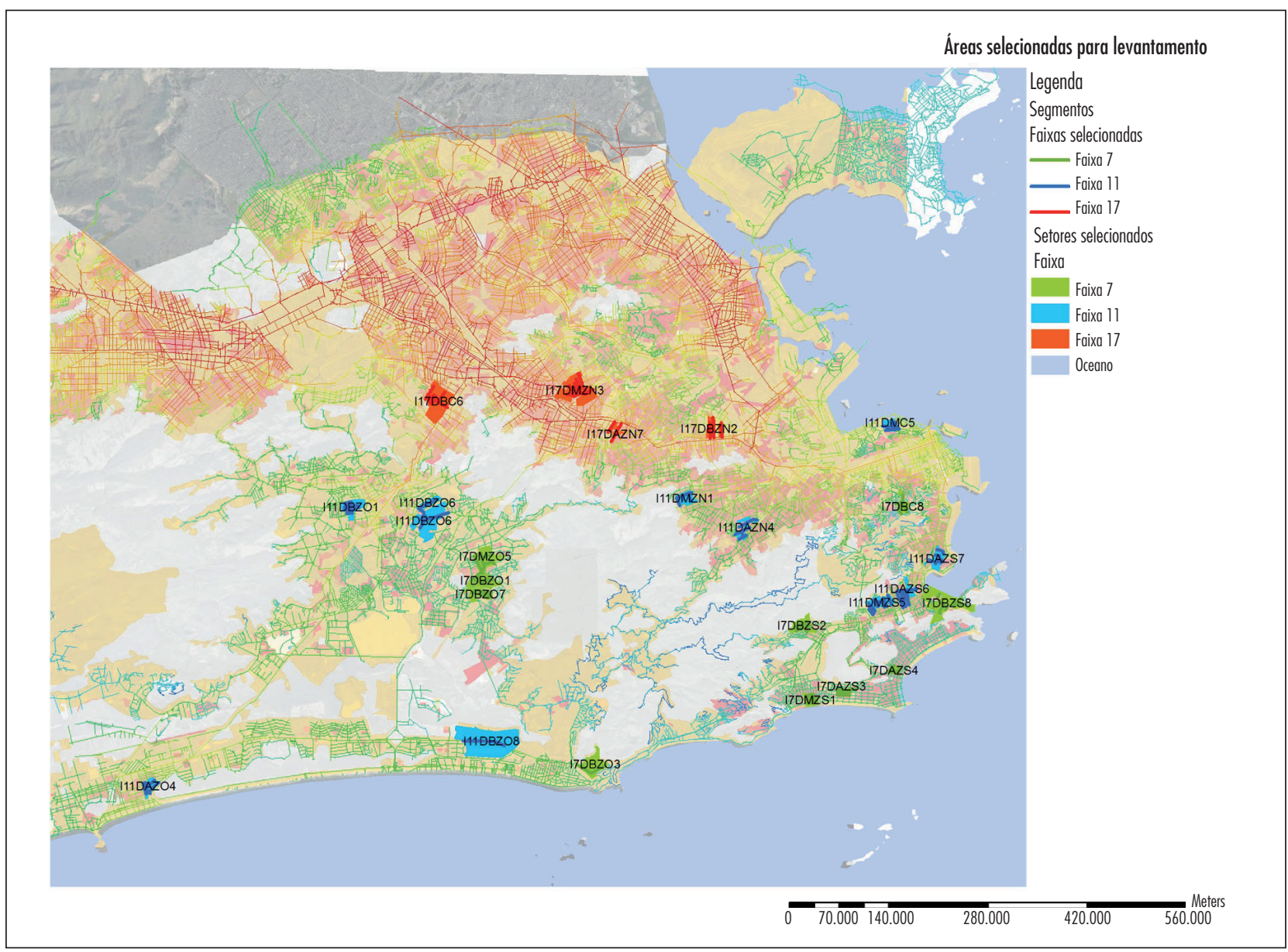

Figura 13 - Áreas selecionadas para levantamento ${ }^{10}$

Fonte: NETTO et al., 2012.

\footnotetext{
9 Sorteadas a partir das combinações de acessibilidade e densidade, e o número de segmentos de ruas levantadas (integração RR).

${ }^{10}$ As 24 áreas selecionadas aleatoriamente dentro das três faixas de acessibilidade e densidade em estudo, atendendo a condição da variedade tipológica de interesse aqui.
} 
Nessas áreas, foram contados e medidos os lotes (dimensões e área) e verificado seu tipo de fechamento em relação ao alinhamento do passeio público. Já as edificações foram levantadas com grande grau de detalhe: dimensões, área, altura, número de unidades (economias), portas, janelas, garagens e algumas relações convencionalmente estabelecidas entre essas medidas básicas na área da arquitetura, tais como a taxa de ocupação, o índice de aproveitamento, um novo índice de continuidade de fachadas e outros. Confrontamos as distribuições dessas variáveis e suas intensidades (cerca de 50 variáveis arquitetônicas e urbanas e 15 variáveis socioeconômicas resumidas no Quadro 1) com as ferramentas da estatística: colidimos variáveis e observamos o comportamento desses confrontos, por vias gráficas e correlações numéricas.

\section{Indícios da relação entre aspectos da arquitetura e das dinâmicas sociais locais}

Considerando a complexidade e o número de fatores urbanos que interferem na geração dos fenômenos socioeconômicos locais, as correlações encontradas entre este conjunto de fatores espaciais com componentes da vitalidade socioeconômica são bastante expressivas. Detalhamos em seguida apenas os resultados das áreas de baixa acessibilidade (faixa 7), que apresentam em geral as correlações mais elevadas. As correlações das áreas de média e alta acessibilidade têm variações intrigantes, seguindo, contudo, a mesma tendência geral ${ }^{11}$.

Nossos achados são preocupantes. Lembrando que correlações baseadas no coeficiente de Pearson variam entre zero e -1 ou +1 (correlação perfeita negativa ou positiva), verificamos que características arquitetônicas tendem a ter correlações consistentes e expressivas com a presença - ou ausência - de pedestres e atividades microeconômicas. Gravemente, o estudo empírico de larga escala no Rio de Janeiro indica ainda que os tipos arquitetônicos se comportam de modo inverso em relação à vitalidade: o tipo (a) contínuo correlaciona positivamente, enquanto o tipo (b) isolado correlaciona
Quadro 1 - Principais variáveis utilizadas no estudo

\begin{tabular}{|c|c|}
\hline Aspectos & Variáveis \\
\hline \multirow[t]{3}{*}{ Tipologia arquitetônica } & Tipo Contínuo (a) \\
\hline & Tipo Isolado (b) \\
\hline & $\begin{array}{l}\text { Tipo Hibrido (c) } \\
\text { Îndice de Diversidade Tipológica }\end{array}$ \\
\hline \multirow[t]{5}{*}{ Permeabilidade das edificaç̦eses } & Garagens $/ \mathrm{m}$ \\
\hline & Garagens/edificação \\
\hline & Portas $/ m$ \\
\hline & Portas/edificacãão \\
\hline & Janelas/m \\
\hline \multirow[t]{5}{*}{ Relação da edificaçã̃o com o Lote } & $\begin{array}{l}\text { Afastamento frontal (médio no segmento } \\
\text { de quadra) }\end{array}$ \\
\hline & Largura do lote \\
\hline & Largura da fachada da edificação \\
\hline & Afastamento lateral \\
\hline & Índice de Continuidade de Fachadas \\
\hline \multirow[t]{3}{*}{ Fechamento dos lotes } & Grade \\
\hline & Muro \\
\hline & Aberto \\
\hline \multirow[t]{2}{*}{ Altura das edificações } & Pavimentos/m \\
\hline & Pavimentos por edificacạ̃o \\
\hline \multirow[t]{3}{*}{ Densidades } & $\begin{array}{l}\text { Arquitetônica (área construída por área } \\
\text { do lote) }\end{array}$ \\
\hline & Economias/m \\
\hline & $\begin{array}{l}\text { Economias por edificacacão } \\
\text { Îndice de Aproveitamento }\end{array}$ \\
\hline \multirow[t]{4}{*}{ Áreas } & $\begin{array}{l}\text { Área do lote (média no segmento de } \\
\text { quadra) }\end{array}$ \\
\hline & Área do térreo \\
\hline & Área da edificação \\
\hline & Taxa de ocupação \\
\hline Parcelamento do Solo & Lotes $/ \mathrm{m}$ \\
\hline \multirow[t]{4}{*}{ Acessibilidade } & Integração RR \\
\hline & Integraçã̃o RN \\
\hline & Integração R3 \\
\hline & Escolha RR \\
\hline
\end{tabular}

\footnotetext{
${ }^{11}$ Veja o detalhamento dos dados das faixas de acessibilidade média e alta em <http://urbanismo.arq.br/metropolis/?p=1680 e http://arq.ufsc.br/infoarq/?p=345>.
} 
Quadro 1 - Principais variáveis utilizadas no estudo

\begin{tabular}{ll}
\hline Aspectos & Variáveis \\
\hline Atividade pedestre & Movimento de pedestres (médio no \\
& segmento) \\
& Grupos de pessoas paradas \\
& Indivíduos parados \\
& Residencial \\
Atividade microeconômica & Comercial \\
& Serviço \\
& Comércio e serviço \\
& Institucional \\
& İndice de Diversidade de Atividades \\
\hline
\end{tabular}

Fonte: Dados da pesquisa. negativamente com praticamente todos os fatores de vitalidade urbana considerados. Uma seleção de confrontos entre fatores arquitetônicos e socioeconômicos e seus graus de correlação simples é apresentada na Tabela 1 (graduação de cinzas mostra diferenças na intensidade das correlações).

Vejamos o que as correlações, como indicadores da coincidência entre fatores, nos dizem:

Temos correlações positivas entre edifícios do tipo (a) contínuo com o movimento pedestre e com a presença de térreos com comércios ou serviços. Já a correlação entre o edifício tipo (b) isolado e movimento pedestre e comércios ou serviços em térreos é significantemente negativa ${ }^{12}$, revertendo quase diametralmente o tipo (a). Também dando suporte às hipóteses que apontamos, o tipo (c) híbrido apresenta correlação quase nula ou ligeiramente positiva com movimento pedestre atividades comerciais e serviços ${ }^{13}$.

Tabela 1 - Correlações de Pearson entre aspectos arquitetônicos e socioeconômicos (faixa de acessibilidade baixa)

\begin{tabular}{|c|c|c|c|c|c|c|c|c|c|c|c|}
\hline & & \multicolumn{3}{|c|}{ Variáveis Pedestres } & \multicolumn{4}{|c|}{ Atividades socioeconômicas nos Térreos } & \multicolumn{3}{|c|}{ Tipo Arquitetônico } \\
\hline & & $\begin{array}{l}\text { Mov. } \\
\text { pedestre }\end{array}$ & Grupos Estat & Indiv Estat & Resid & Comerc & $\begin{array}{l}\text { Comerct } \\
\text { Servictos }\end{array}$ & Diversid & Contín & Isolado & Hibrido \\
\hline \multirow[t]{5}{*}{ Tipo arq. } & Contínuo & 0.327 & 0.447 & 0.407 & -0.413 & 0.293 & 0.422 & 0.428 & 1 & -0.983 & -0.054 \\
\hline & Isolado & -0.342 & -0.469 & -0.415 & 0.446 & -0.318 & -0.449 & -0.456 & -0.983 & 1 & -0.128 \\
\hline & Hibrido & 0.094 & 0.140 & 0.060 & -0.200 & 0.146 & 0.163 & 0.172 & -0.054 & -0.128 & 1 \\
\hline & Ind Cont & 0.418 & 0.430 & 0.462 & -0.316 & 0.353 & 0.380 & 0.276 & 0.460 & -0.436 & 0.017 \\
\hline & Afast Front & -0.424 & -0.393 & -0.394 & 0.2275 & -0.386 & -0.290 & -0.217 & -0.317 & 0.339 & -0.129 \\
\hline \multirow{3}{*}{$\begin{array}{l}\text { Lote: Limite } \\
\text { Rua }\end{array}$} & Muro & -0.477 & -0.506 & -0.460 & 0.472 & -0.454 & -0.496 & -0.449 & -0.428 & 0.423 & 0.012 \\
\hline & Grade & -0.196 & -0.096 & -0.113 & 0.150 & -0.273 & -0.199 & 0.078 & 0.227 & -0.207 & -0.099 \\
\hline & Lote aberto & 0.627 & 0.589 & 0.554 & -0.592 & 0.657 & 0.650 & 0.410 & 0.286 & -0.295 & 0.055 \\
\hline \multirow{2}{*}{$\begin{array}{l}\text { Portas e } \\
\text { janelas }\end{array}$} & Dens Portas & 0.683 & 0.446 & 0.499 & -0.533 & 0.610 & 0.577 & 0.408 & 0.551 & -0.567 & 0.111 \\
\hline & Dens Janelas & 0.725 & 0.512 & 0.677 & -0.466 & 0.486 & 0.524 & 0.338 & 0.298 & -0.301 & 0.028 \\
\hline \multirow[t]{2}{*}{ Densidade } & Dens Arq & 0.517 & 0.473 & 0.508 & -0.223 & 0.326 & 0.284 & 0.216 & 0.428 & -0.436 & 0.060 \\
\hline & Dens Econ & 0.652 & 0.369 & 0.498 & -0.360 & 0.390 & 0.427 & 0.256 & 0.173 & -0.172 & 0.003 \\
\hline \multirow{3}{*}{$\begin{array}{l}\text { Variáveis } \\
\text { Pedestres }\end{array}$} & Mov.Pedest & 1 & 0.553 & 0.628 & -0.682 & 0.796 & 0.739 & 0.336 & 0.327 & -0.342 & 0.094 \\
\hline & Grupos Estat & 0.553 & 1 & 0.776 & -0.646 & 0.669 & 0.658 & 0.510 & 0.447 & -0.469 & 0.140 \\
\hline & Indiv Estat & 0.628 & 0.7763 & 1 & -0.563 & 0.599 & 0.616 & 0.459 & 0.407 & -0.415 & 0.060 \\
\hline
\end{tabular}

Fonte: Dados da pesquisa.

\footnotetext{
${ }^{12}$ Todas as correlações têm significância com valor $\mathrm{p}<$ 0,001. 0 teste de significância estatística (o “valor p" de cada correlação) examina a probabilidade de um resultado observado se repetir ou surgir por mera coincidência. Valores $p \geq 0,05$ não têm significância estatística, segundo o parâmetro convencionalmente adotado de $95 \%$ de confiança.

${ }^{13}$ As correlações de fatores socioeconômicos com o tipo híbrido não obtiveram significância estatística (valores encontrados $\mathrm{p}>0,05$ ) em função de sua baixa presença nas 24 áreas examinadas.
} 
Investigamos ainda a relação entre diversidade de atividades (residencial, comércio, serviços e institucional) tanto em térreos quanto em pavimentos superiores, e variáveis pedestres como movimento e presença de grupos estáticos no espaço público da rua. A correlação entre diversidade de atividades em térreos e movimento pedestre é positiva, assim como a correlação com grupos estáticos. Fora dessa tabela-resumo, nossos dados mostram que a diversidade de atividades em pavimentos superiores também é um fator que coincide com movimento pedestre $(0,345)$ e, de modo mais marcante, com a presença de grupos estáticos na rua $(0,475)^{14}$, dando suporte à hipótese jacobiana da associação urbana entre diversidade de atividades e vitalidade.

E quanto às relações entre diversidade de atividades e tipos arquitetônicos? Encontramos correlações bastante positivas entre diversidade no térreo e o tipo contínuo; já a correlação com o tipo isolado é significativamente negativa. Temos, assim, outra reversão entre o comportamento apontando a redução drástica de diversidade para áreas de predominância do tipo (b). A correlação entre diversidade de atividades em pavimentos superiores e tipos intensifica essa tendência.

A porosidade da fachada é um dos itens clássicos da ideia jacobiana de vitalidade urbana. Nossos dados confirmam isso. A densidade de portas tem fortes correlações com movimento de pedestres, grupos estáticos, comércios, comércio e serviços e diversidade de atividades no térreo. A densidade de janelas também apresenta correlações altíssimas com movimento de pedestres, altas com grupos estáticos, atividades comerciais e serviços, e em menor grau com diversidade de atividades no térreo. A correlação entre a densidade de janelas dos pavimentos superiores e movimento pedestre é de 0,420 . As janelas do térreo, isoladamente, pouco estimulam o pedestre $(0,158)$; mas em associação fazem muita diferença: a correlação com movimento pedestre somando as janelas de todos os andares é das mais altas encontradas. 0 pedestre parece preferir caminhar onde há janelas presentes nos dois níveis. Ainda, a densidade de janelas coincide fortemente com lotes abertos $(0,674)$ e com a continuidade de fachadas $(0,549)$.
Agora vejamos como itens de fachada se relacionam com os tipos arquitetônicos. A correlação da densidade de portas com o tipo contínuo é expressivamente positiva, e o inverso para o tipo isolado. Já entre densidade de janelas e tipos, temos ligeira queda.

A combinação entre correlações entre variáveis socioeconômicas, fatores de fachada e tipos mostra que o tipo contínuo favorece a porosidade entre arquitetura e espaço público, e que essa porosidade é associada positivamente com a presença de pedestres e atividades - em proporção inversa a do tipo isolado.

Tal tendência é similar para a interface edifício-espaço público, identificada nos afastamentos frontais e bordas entre lote e passeio. Quanto ao item muros, suas correlações com movimento de pedestres e com grupos estáticos na rua são bastante negativas, assim como sua correlação com atividades de comércio e serviços de térreo e diversidade. Grades apresentam correlações negativas, mas em menor grau com movimento pedestre, grupos estáticos na rua, comércio e serviços de térreo e diversidade. Quanto aos lotes abertos, suas correlações com movimento de pedestres e grupos estáticos são fortemente positivas, assim como suas correlações com atividades de comércio e serviços de térreo, e sua diversidade.

Essas observações confirmam a noção de senso comum de que muros e grades impactam negativamente o uso pedestre do espaço público e as atividades comerciais ao nível do térreo, sendo mais intensos os impactos do primeiro. As correlações entre muros e tipos mostram forte associação entre recuos e muros e o tipo isolado - hoje o preferido pelo mercado imobiliário. Esses fatores de permeabilidade entre arquitetura e rua apresentam estatisticamente uma relação problemática com aspectos sociais e econômicos locais. Contrariamente, lotes abertos correlacionam positivamente com tipos contínuos.

Como as características das edificações se relacionam entre si? As correlações entre tipos e densidade arquitetônica são consideravelmente positivas com o tipo contínuo e negativas com o isolado. Os dados mostram uma combinação positiva para a

\footnotetext{
${ }^{14}$ Todas as correlações têm significância $\mathrm{p}<0,05$, exceto onde indicado.
} 
vitalidade entre densidades, lotes abertos e proximidade de fachadas entre si e com a rua ${ }^{15}$.

\section{Quais os aspectos arquitetônicos mais relevantes no movimento pedestre?}

Buscamos, a seguir, identificar os fatores arquitetônicos mais relevantes para a explicação da vitalidade urbana explorando regressões lineares múltiplas, um confronto de todos os fatores entre $\mathrm{si}^{16}$. Nesse momento, usamos apenas o movimento pedestre como aspecto da vitalidade. Selecionamos em seguida um conjunto de fatores arquitetônicos amplo o bastante para responder pelo movimento pedestre - densidades, atividades e componentes da forma arquitetônica.

Nas áreas de baixa acessibilidade examinadas, a regressão múltipla entre movimento pedestre e quatro fatores arquitetônicos (densidade de economias, atividades comércio e serviço no térreo, lote aberto e densidade de portas no térreo) apresenta um coeficiente de determinação ajustado ${ }^{17}$ $\left(R^{2}\right)$ de 0,703 . Esse resultado bastante elevado indica que apenas esses fatores responderiam por grande parte da movimentação pedestre. Esses fatores podem ser substituídos e estimados novamente. Nas áreas de acessibilidade média, mantendo três destes fatores e substituindo a densidade de portas pelo tipo contínuo, temos um $\mathrm{R}^{2}$ ajustado menor, de 0,482 , similar àquele encontrado nas áreas de acessibilidade alta com os mesmos fatores, um $\mathrm{R}^{2}$ ajustado de 0,497 .

0 resultado para a amostra agregada (todas as faixas) traz um $\mathrm{R}^{2}$ ajustado de 0,585 , bastante alto, com significância estatística atestada, e capacidade preditiva dos fatores arquitetônicos analisados sobre a intensidade do movimento pedestre ${ }^{18}$. Essencialmente, essa análise mostra que um número pequeno de fatores arquitetônicos pode responder por parte substancial das distribuições do movimento pedestre no Rio de Janeiro. Uma das utilidades da análise é entender qual o potencial preditivo de um fator em relação ao seu comportamento e intensidades, mesmo em outras situações.

Alguns fatores, reunidos, parecem explicar grande parte do movimento pedestre. Como podemos entender o peso de cada um deles, e de todos no conjunto entre si? Há ferramentas interessantes capazes de mostrar exatamente o grau de contribuição de arranjos de características arquitetônicas na explicação do movimento pedestre. Utilizamos de forma experimental um tipo de regressão múltipla (PLS) que, à maneira de uma análise de componentes principais, reconhece agrupamentos de variáveis altamente correlacionadas entre si e com elas gera construtos capazes de representar a quase totalidade das variáveis independentes. Essa análise mostra graficamente as intensidades das variáveis em seus papéis no movimento pedestre a partir da distribuição de eixos (Figura 14), fatores positivos à direita, negativos à esquerda. A extensão dos eixos mostra o grau de importância de cada fator na predição do movimento pedestre.

A análise confronta o papel de todos os fatores entre si, incluindo as próprias variáveis "respostas" - movimento pedestre, indivíduos e grupos estáticos e em interação - para a explicação de qualquer outra variável. Lotes abertos, comércios e serviços, diversidade, densidade de janelas, a continuidade de fachadas e o tipo contínuo aparecem agrupados em um componente com papel claramente positivo. Muros, uso residencial exclusivo, afastamentos lateral e frontal e o tipo isolado aparecem no componente com impactos negativos sobre o movimento pedestre.

A relação entre as variáveis arquitetônicas pode ser evidenciada mais diretamente por outro tipo de análise, a de aglomerados (cluster analysis), técnica utilizada para agrupar itens similares, diferindo dos itens de outros aglomerados, na forma de similaridades nas suas distribuições, sem que haja uma

\footnotetext{
${ }^{15}$ Veja em detalhe essas correlações nos anexos disponibilizados em <http://urbanismo.arq.br/metropolis/?p=1680 > e <http://arq. ufsc.br/infoarq/?p=345>.

${ }^{16}$ A modelagem por regressão visa interpretar e prever uma ou mais variáveis dependentes (resposta) por meio de variáveis independentes (preditoras).

${ }^{17}$ Coeficiente de determinação (R2) é a proporção de variação em um fator que é explicada pelo comportamento de outros fatores estudados conjuntamente. O R2 ajustado é uma modificação do R2 usada com o intuito de compensar a adição de novas variáveis ao estudo, penalizando-o quando essas novas variáveis não contribuem para o poder explicativo do modelo.

${ }^{18}$ Veja a análise de regressões múltiplas detalhadas nos Anexos disponíveis em: <http://urbanismo.arq.br/metropolis/?p=1680 e http://arq.ufsc.br/infoarq/?p=345>.
} 


\section{Gráfico de cargas da Regressão PLS: Resposta = PEDESTRES (Todas as faixas de acessibilidade)}

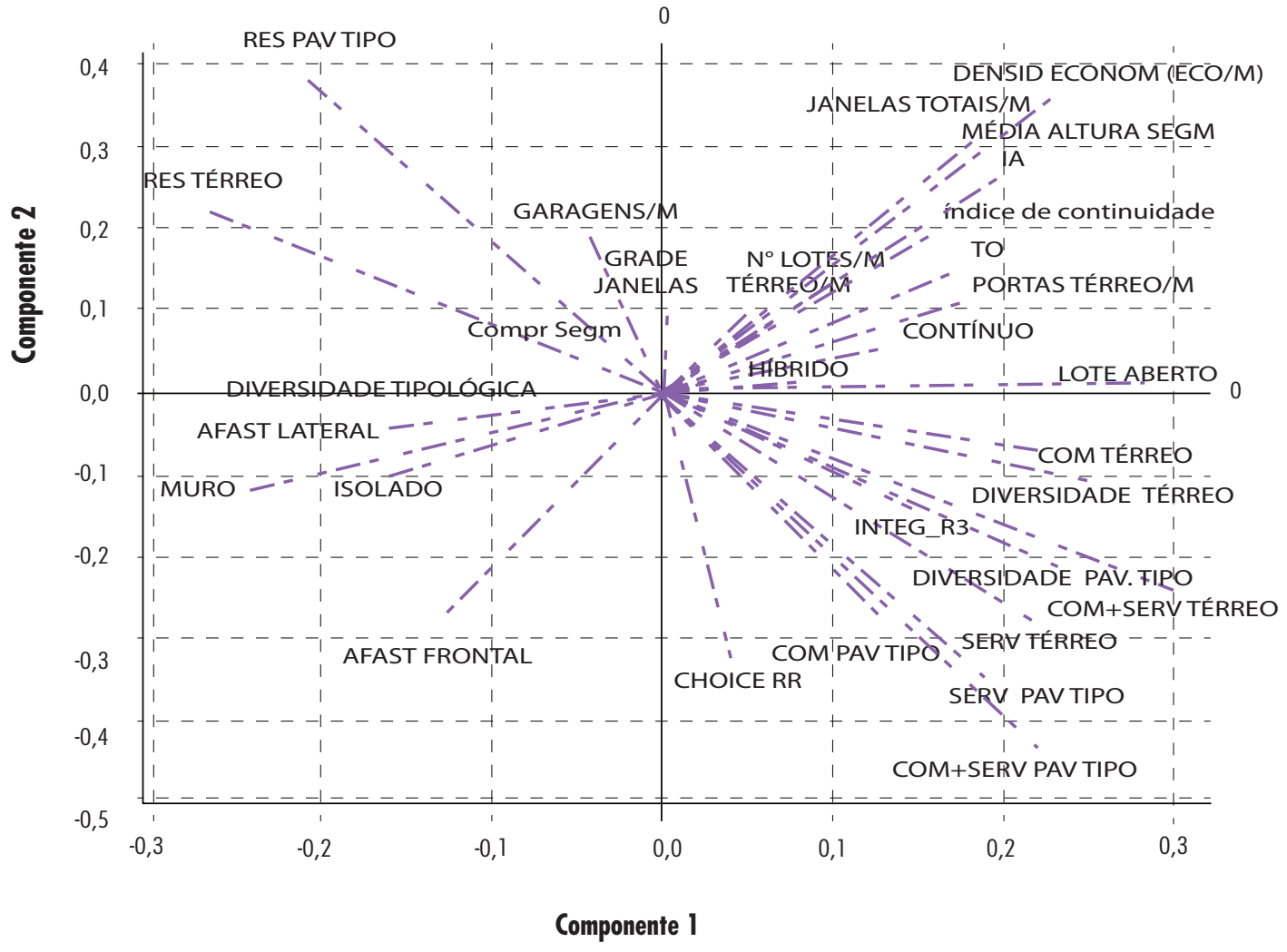

Figura 14 - Análise de regressão com capacidade preditiva

Fonte: Dados da pesquisa.

"resposta" ou variável independentemente a ser explicada. 0 resultado dessa busca por semelhanças pode ser visualizado na Figura 15. O dendograma mostra como as variáveis são agrupadas em função de seus coeficientes de correlação; ali, no primeiro nível de agregação (de cima para baixo), temos dois grandes grupos com similaridade interna.

Destes, temos outros subgrupos que se bifurcam em: (1) grade e janelas de térreo, garagens, largura dos lotes e de fachadas, com similaridade em torno de 50\%; e (2) muro, afastamento lateral e afastamento frontal, com similaridade em $70 \%$. 0 outro braço do dendograma bifurca-se em: (1) lote aberto e densidade de portas, índice de continuidade e taxa de ocupação, com similaridade em torno de 70\%; e
(2) densidade de janelas e de economias, e índice de aproveitamento e altura média, com similaridade em torno de 80\%. Esses são os fatores arquitetônicos que aparecem mais frequentemente associados nas áreas analisadas no Rio.

O que essa informação significa em termos das relações entre características arquitetônicas e estímulos ou danos à vitalidade urbana? Na busca por um arranjo de características que melhor responda à vitalidade, encontramos concentrações em torno de um tipo contínuo, aberto e bastante permeável em sua fachada: a continuidade da linha de interface edifício-rua é a chave da tipologia enquanto elemento ativo na vitalidade. A queda da presença de pedestres e atividades microeconômicas aparece 




Figura 15 - Agregação utilizando o coeficiente de correlação entre todos os fatores arquitetônicos das ruas analisadas, avaliando a similaridade e coincidência de suas distribuições

Fonte: Dados da pesquisa.

consistentemente associada a arquiteturas que apresentam descontinuidade de fachadas, afastamentos, lotes de maior largura e muros. Em outras palavras, ainda que itens como muros possam ser encontrados em diferentes tipos arquitetônicos, a análise mostra sua associação mais frequente com um tipo particular - o isolado. A combinação dessas análises de regressão nos leva a concluir que dois "pacotes" de características arquitetônicas são bastante distintos, e ambos se relacionam de modo bastante distinto com o uso pedestre do espaço público.

\section{Fundamentos para uma teoria probabilística dos efeitos sociais da arquitetura}

Um problema fundamental para uma teoria sistemática dos efeitos sociais da arquitetura seria o da extensão desses efeitos ${ }^{19}$. Conhecer essa extensão implica encontrar regularidades e intensidades consistentes em diferentes contextos urbanos. Essa extensão está naturalmente sujeita à diversidade de fatores socioespaciais ativos na cidade.

Nossos resultados apontam para uma correspondência mais que coincidente entre aspectos espaciais e sociais: sugere a possibilidade de relações causais ativas, as quais estenderiam as relações entre distância e interação ativas no campo da ação econômica encontradas pela geografia e economia espacial até o nível do corpo e dos espaços imediatos da nossa prática: nossos entornos no espaço urbano.

Relações dessa natureza são certamente difíceis de demonstrar, e estão entre as coisas mais polêmicas em estudos arquitetônicos e urbanos. Correlações não demonstram que um aspecto $\mathrm{C}$ causa um efeito E. Esse é um problema usual na chamada teoria da probabilidade. Uma trama de causas e efeitos pode envolver muitos caminhos ao mesmo tempo, tornando frequentemente impossível localizar ou isolar relações específicas. Vejamos alguns casos: (1) fatores X (digamos, morfologia arquitetônica) e

\footnotetext{
${ }^{19}$ As proposições desta seção são derivadas de Netto (no prelo).
} 
Y (acessibilidade) têm efeitos simultâneos sobre Z (atividade comercial). A correlação de um fator pode esconder a influência de outro. (2) X tem efeitos simultâneos sobre Y e Z; Z também afeta Y, e X afeta Y por dois caminhos. (3) Fatores causais C e D afetam independentemente os mesmos fatores A e B, que também se afetam entre si (Figura 16).

Como então sair desse problema e identificar relações específicas? Uma relação causal implica que elementos sejam, conjuntamente, suficientes para gerar efeitos. As conjunções possíveis devem ser testadas estatisticamente, sobretudo via análises de regressão, confrontando fatores entre si. Esses métodos permitem testar combinações, isolar fatores entre si, e encontrar regularidades emergentes desses confrontos. Essas regularidades e as propriedades dos eventos envolvidos sugerem, por exemplo, que, se mantivermos outros fatores urbanos constantes, quanto maior a densidade do espaço construído, mais encontros; quanto menor a densidade urbana, menor o potencial probabilístico do encontro ${ }^{20}$. Essa relação basilar entre forma urbana e dinâmica social local ainda encontra desdobramentos em seus componentes arquitetônicos e efeitos socioespaciais (Figura 17).

A investigação da probabilidade de efeitos da arquitetura deve incluir também causas negativas - $a$ possibilidade de C inibir E em um contexto (Figura 18).

Concluindo, se a teoria da probabilidade está correta ao afirmar que

\section{há relação causal entre $C$ e E quando $C$ aumenta a probabilidade de E,}

componentes da forma urbana e arquitetônica podem ser considerados fatores causais da copresença ao aumentar sua probabilidade. Sua condição de

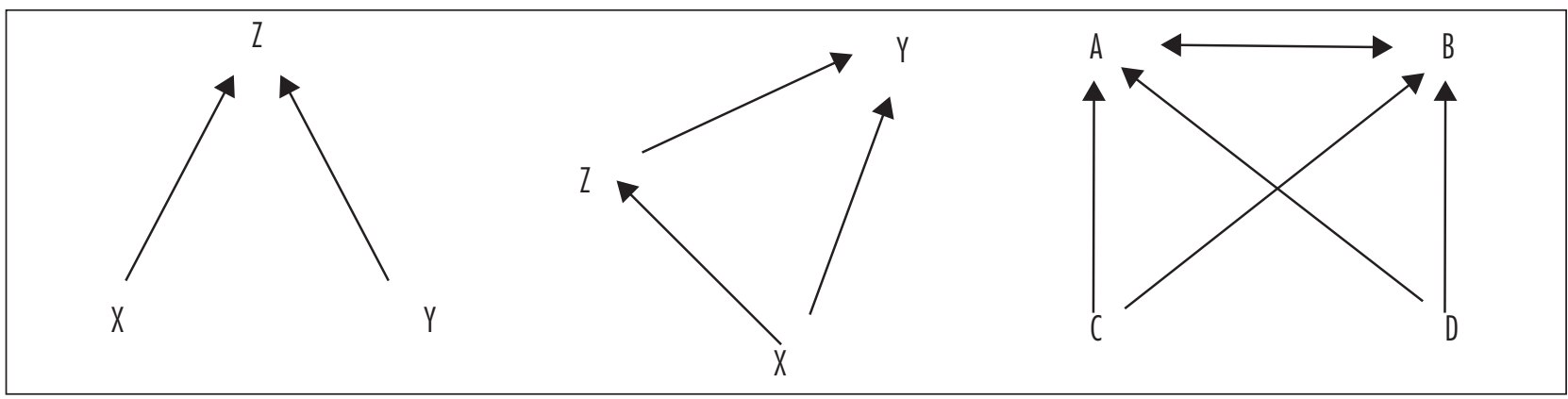

Figura 16 - Exemplos de relações de causalidade

Fonte: Dados da pesquisa.

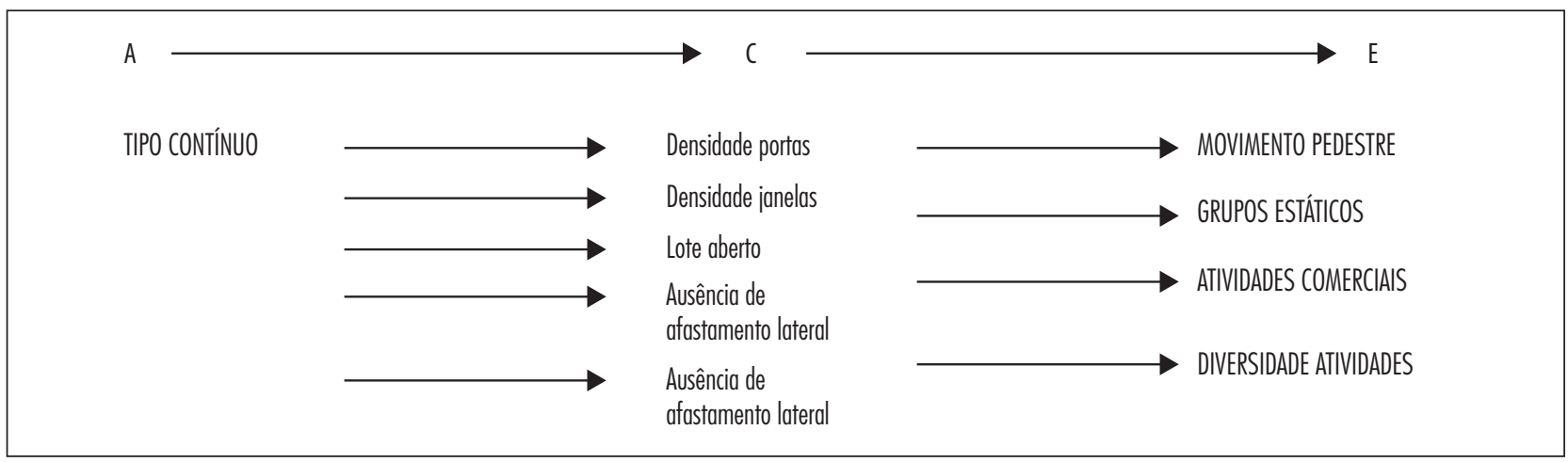

Figura 17 - Causalidades possiveis, dentro da trama de relações não causais e outras contingências urbanas

Fonte: Dados da pesquisa.

\footnotetext{
${ }^{20}$ Essas implicações podem ser evidenciadas de modo "contrafatual": se não houvesse proximidade para colocar corpos em copresença, interações não aconteceriam; se não houvesse densidade construída suficiente para generalizar a proximidade entre corpos, encontros e interações não aconteceriam com intensidade.
} 


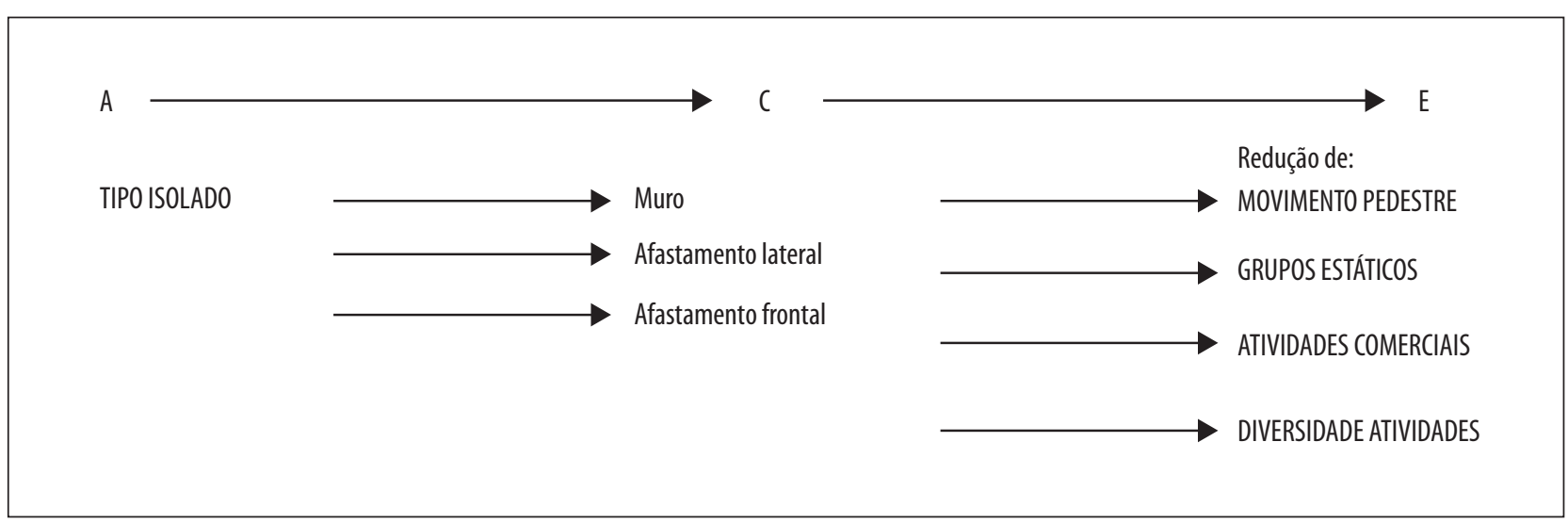

Figura 18 - Implicações causais do tipo isolado

Fonte: Dados da pesquisa, 2012.

ocorrência sugere que esse seria o caso. A formação de cidades e suas espacialidades é um modo de superar a fricção fundamental da distância e da extensão, e de moldar a aderência do espaço sobre a prática, para que a interação ocorra com (menos ou mais) fluidez e intensidade. Distância e a proximidade geram condições para a interação, que pode se reduzir ou intensificar em função delas. Essa ideia é tão antiga quanto a própria geografia econômica, e latente já na ideia aristotélica da formação da polis (SOJA, 2000). Nosso estudo mostra que ela parece se manifestar de maneira muito sensível, o tempo todo, também na espacialidade imediata à atuação dos atores na cidade.

Essa seria a linha de causalidade material mais profunda entre espaço e dinâmicas sociais. Mas essa relação de efeitos mútuos na escala local depende de estruturações que vão além dela - são parte de um processo realmente sistêmico, urbano. Encontramos aqui uma condição material: a rigidez do espaço não pode ser ignorada, mas moldada para que nossa ação conjunta possa emergir. A extensão e a rigidez podem ser superadas na forma de estruturas espaciais de acesso entre formas construídas moldadas para aproximar e permitir a ação conjunta.

Cidades são meios de dobrar a extensão do espaço em estruturas que ampliam a fluidez e intensidade da interação. A linha de causalidade original que atravessa a prática e a experiência humana é assim "curvada" pela ação humana na forma de complexos espaciais que assumem a forma de cidades, mas ela não se replica da mesma forma quando espacialidade e prática ganham complexidade. O próprio moldar das condições de extensão e rigidez fundamentais do espaço na forma urbana adiciona novas possibilidades à praticas; a partir disso, suas relações podem ser potencializadas, tanto baseadas em causalidades quanto descoladas da aderência do espaço, em relações livres da influência do espaço.

Entretanto, como "dobras do espaço em espaço urbano", tais estruturas geram novas extensões que precisam também ser superadas, ainda que com fluidez e intensidade naturalmente maiores. Temos como resultado, entretanto, uma redução do esforço do corpo em relação ao espaço, explorando as tensões corpo-espaço e entre formas construídas - que inicia na proximidade entre elas (e é enfraquecida mesmo em suas pequenas distâncias) e chega à porosidade do edifício ao espaço público e seu efeito sobre movimento e copresença.

Paralelamente, outras possibilidades de relação entre espaço e prática humana se abrem de modo cada vez menos linear, sobretudo quando a ambos é conferida maior complexidade e heterogeneidade ao serem produzidos na forma de espaço urbano e sistemas de práticas. Essas estruturas espaciais permitem alargar as possibilidades da prática e gerar diversidade na relação entre práticas - uma relação baseada em efeitos, mas que abraça também o imprevisível. Essas estruturas oportunizam também o convívio de causalidade e contingência em ações livres de determinação material, mas nem por isso livres da condição material para ocorrerem em maior ou menor fluidez e intensidade. Há uma tensão muito sutil e frágil aqui: uma tensão 
socioespacial manifesta entre corpo e arquitetura. Uma teoria probabilística, capaz de identificar $a$ extensão da tensão espaço-corpo na forma de efeitos sociais da morfologia arquitetônica compartilhada mesmo em diferentes contextos, possibilitaria antecipar tais efeitos, e considerá-los já nos momentos do planejamento, projeto e produção da forma urbana.

\section{Cidade: contingência, causalidade, contexto - conclusão}

Cidades são fenômenos nos quais há um enorme número de fatores ativos, com implicações e interdependências e efeitos mútuos. Reconhecendo os cuidados do argumento antideterminismo, devemos rejeitar a tese de implicações simples de causa e efeito entre fatores. Processos urbanos têm particularidades e diferenças assentadas em condições contingenciais, como em contextos distintos e nos desdobramentos de ações e práticas sociais no tempo e no espaço cujas trajetórias são impossíveis de prever. A morfologia arquitetônica é colhida em emaranhados dos quais reconhecemos apenas parte.

Entretanto, o estudo das relações entre certos fatores espaciais e sociais aponta para a possibilidade de termos ao mesmo tempo indeterminação e causalidade entre arquitetura e a vitalidade urbana. Nosso método de confrontos entre aspectos urbanos via o rigor da estatística tem mostrado que fluxos pedestres e a presença de atividades econômicas variam conforme as variações de componentes da arquitetura.

Esses resultados sugerem que a arquitetura faz diferença nos fenômenos socioeconômicos locais: aspectos como a proximidade entre edifício e passeio, entre edifícios, sua permeabilidade e atividades da forma parecem adicionar tensão entre espaço construído e aberto, entre arquitetura e corpos usando o espaço público - as condições materiais do potencial de copresença e interação social e microeconômica. Por outro lado, arranjos caracterizados por espaçamentos entre edifícios e entre estes e os canais da rua enfraquecem-se como suporte e atração para a manifestação da copresença. Esses achados permitem que se possa avançar também na teoria probabilística dos efeitos sociais da arquitetura. 0 fato de que, entre todas essas complexidades, encontramos regularidades e relações não deixa de ser surpreendente - fortes indícios do papel da morfologia arquitetônica, e fortes traços da existência de relações não contingenciais entre sociedade e espaço operando já na escala do edifício e seu entorno.

Mas esses achados nos levam a outro questionamento: eles seriam os mesmos em diferentes contextos sociais e geográficos? Encontramos relações marcantes entre aspectos sociais e espaciais em diferentes contextos de uma mesma cidade, ainda que com diferentes intensidades. Um segundo momento desta pesquisa buscará entender se diferenças contextuais entre cidades, bem como diferenças de grupo social, hábitos e valores e formas de sociabilidade, podem afetar a extensão dos efeitos sociais da arquitetura.

Esses resultados sugerem algo ainda mais importante: a urgente atenção à tipologia produzida atualmente em nossas cidades - predominantemente isolada, empiricamente associada a condições de diluição da vitalidade urbana - na esfera técnica do planejamento urbano e na esfera da opinião pública. Este artigo espera estimular e contribuir com suporte teórico e empírico para novos debates sobre forma arquitetônica e legislação urbanística em nosso país.

\section{Nota}

A análise estatística completa e os dados deste estudo empírico podem ser encontrados em: $<$ http://urbanismo.arq.br/metropolis/?p=1680 e http://arq.ufsc.br/infoarq/?p=345>.

\section{Agradecimentos}

Agradecemos ao CNPq pelo apoio imprescindível para a realização desta pesquisa empírica; a Paulo Rheingantz, por uma crítica que muito contribuiu à atual apresentação deste trabalho; a Romulo Krafta pela crítica e suporte constantes; e a Cássio Freitas pelo suporte na definição estatística das amostragens. Agradecemos também a Maíra Pinheiro e Renato Remiro, nossos assistentes de pesquisa, e a Hetecliphe Neto, Nathalia Gonçalves, Luisa Seixas, Paula Moreira, Taiana Milward, Thiago da Costa e 
Samuel Jachetti, estudantes da Universidade Federal Fluminense (UFF) que investiram grande esforço nos levantamentos. Sem seu rigor, não teríamos condição de obter dados dessa significância, nem alcançaríamos esse conhecimento. (Esperamos tê-los contaminado com o vírus da curiosidade científica, em retorno).

\section{Referências}

AGUIAR, D. Alma espacial: o corpo e o movimento na arquitetura. Porto Alegre: Ed. UFRGS, 2010.

FLORIDA, R. For Creative Cities, the Sky Has Its Limit. Wall Street Journal, 27 jul. 2012. Disponível em: <http://online.wsj.com/article/SB10000872396390443477104577 551133804551396.html>. Acesso em: 28 ago. 2012.

GEHL, J. Life between buildings: using public space. Washington, DC: Island Press, 2011.

GLAESER, E. The triumph of the city: how our greatest invention makes us richer, smarter, greener, healthier and happier. New York: Penguim, 2010.

GORDON, P.; IKEDA, S. Does density matter? In: ANDERSSON, D.; ANDERSSON, A.; MELLANDER, C. (Ed.). Handbook of Creative Cities. [S.l.]: Edward Elgar Pub, 2011.

HANSEN, W. G. How accessibility shapes land use. Journal of the American Institute of Planners. v. 25, n. 2, p. 73-76, 1959.

HILLIER, B.; PENN, A.; HANSON, J. Natural movement: or, configuration and attraction in urban pedestrian movement. Environment and Planning B: Planning and Design, v. 20, n. 1, p. 29-66, 1993.

HILLIER, B. Space is the machine. Cambridge: Cambridge University Press, 1996.

HILLIER, B.; HANSON, J. The social logic of space. Cambridge: Cambridge University Press, 1984.

HOLANDA, F. de. 0 espaço de exceção. Brasília: Ed. UnB, 2002.
JACOBS, J. Morte e vida de grandes cidades. São Paulo: Martins Fontes, 2000. (Obra originalmente publicada em 1961).

NETTO, V. M. O efeito da arquitetura: impactos sociais, econômicos e ambientais de diferentes configurações de quarteirão, Arquitextos, v. 07907, ano 7, dez. 2006.

NETTO, V. M. Cidade e Sociedade: as tramas da prática e seus espaços. Porto Alegre: Editora Sulina. (No prelo).

NETTO, V. M. et al. The convergence of patterns in the city: (isolating) the effects of architectural morphology on movement and activity. In: INTERNATIONAL SPACE SYNTAX SYMPOSIUM, 8., 2012. Santiago. Proceedings... Santiago: Universidad Catolica de Chile, 2012.

PENN, A. et al. Configurational modelling of urban movement networks. Environment \& Planning B, v. 25, n. 1, p. 59-84, 1998.

SABOYA, R.; VARGAS, J. C. Tipos arquitetônicos e vitalidade urbana: um estudo sobre as possíveis relações entre a arquitetura e o uso dos espaços públicos. In: ENCONTRO DA ASSOCIAÇÃO NACIONAL DE PESQUISA E PÓS-GRADUAÇÃO EM ARQUITETURA E URBANISMO, 2., 2012, Natal. Anais... Natal: UFRN, 2012.

SANTOS, C. N.; VOGEL, A. Quando a rua vira casa: a apropriação de espaços de uso coletivo em um centro de bairro. 3. ed. São. Paulo: Projeto FINEP; IBAM, 1985.

SOJA, E. Postmetropolis: critical studies of cities and regions. Oxford: Blackwell, 2000.

VARGAS, J. C. B. Densidade, paisagem urbana e vida da cidade: jogando um pouco de luz sobre o debate porto-alegrense. Arquitextos, v. 03907, ano 4, ago. 2003.

WEBER, A. Theory of the location of industries. Chicago: University of Chicago Press, 1909.

Recebido: 27/08/2012

Received: 08/27/2012

Aprovado: 01/10/2012

Approved: 10/01/2012 